\title{
REVIEW: STUDY THE ROLE OF CHINA ACUPUNCTURE AND "GI" ACUPUNCTURE AS AN ALTERNATIVE AND COMPLEMENTARY THERAPY IN THE TREATMENT
}

\author{
Risna Agustina ${ }^{1, *}$, Andreanus A. Soemardji², Felesia Fanty², Lia Amalia² \\ ${ }^{1}$ Fakultas Farmasi, Universitas Mulawarman, Samarinda, Kalimantan Timur, 75119, \\ Indonesia \\ ${ }^{2}$ Sekolah Farmasi Institut Teknologi Bandung Bidang Farmakologi \& Klinik \\ J1. Ganesha 10 Labtek VII Bandung 40132 Indonesia \\ *email: aaisyahrisna@yahoo.com
}

\begin{abstract}
This article discusses the scientific literature review on Chinese acupuncture and "GI" acupuncture as an attempt therapy many cases, besides that specifically studied the effectiveness of traditional acupuncture china to stress with "GI" acupuncture. Chinese acupuncture is an acupuncture method that was developed in China since \pm 2000 years ago, while "GI" acupuncture is a method of acupuncture that was developed at the Institute Technology Bandung by acupuncturists Gunawan Ismail (Alm) is slightly different from the traditional Chinese acupuncture, where acupuncture "GI "based on a 7 acupuncture points on the body for ase points determined based of Java massage. Each method studied acupuncture and its role as a therapeutic efforts on a variety of cases, and the results of the study showed some success in handling cases of diseases such as fibromyalgia, stroke and stress. The role of acupuncture GI who want to see here is give the same effectiveness with traditional acupuncture originated from China or even better.
\end{abstract}

Keywords: Acupuncture"GI", Stress, complementary

Submitted on: 28 March 2019

Accepted on: 09 September 2019

DOI: https://doi.org/10.25026/jtpc.v4i6.209

\section{INTRODUCTION}

Acupuncture is a method of traditional medicine originating from China and has been practiced for approximately 2500 years based on the belief that is living things have a vital energy, called "qi", which circulates through 12 invisible energy and is known as a meridian in the body. Imbalance in the flow of qi is believed to be the cause of disease [1].

In 1997, the National Institute of Health stated that it had obtained scientific evidence from the effectiveness of acupuncture and WHO had also received acupuncture as a method of treatment [2].

Acupuncture has developed into various methods of stabbing, such as 
Review: Study the Role of China Acupuncture and "GI" Acupuncture as an Alternative and Complementary Therapy in the Treatment

electrical stimulation techniques, laser acupuncture, "GI" acupuncture, and others. Other acupuncture methods began to be developed in Indonesia by Drs. Gunawan Ismail. This method is called Acupuncture G.I. which is named after the inventor's name. Acupuncture "GI" is one of the acupuncture techniques that was developed based on the acupuncture technique that was previously available and was based on the incorporation of Eastern traditional medicine methods and Western medicine which ultimately results in a simple method with a fewer but deeper penetrating point [3].

The need for acupuncture in developing countries, such as Indonesia is quite significant, due to the lack of health practitioners and medicines. Therefore, the proper use of simple and economical therapy can benefit the community. In addition, acupuncture can be an alternative treatment option for many diseases or conditions where modern conventional medicine is unsatisfactory [4].

\section{MATERIALS AND METHODS}

This paper review about acupunture as an alternative and complementary medicine. The literature was searched between March and December 2018 from the electronic databases including Google Scholar, DOAJ, Science Direct, PubMed and Scopus.

\section{RESULTS AND DISCUSSION}

\section{Acupuncture}

Needling is a term better known in Indonesia than the original term acupuncture. Acupuncture is a method of treatment that utilizes stimuli at acupuncture points and influences the flow of body bioenergy based on the philosophy of balancing the relationship between the surface of the body and organs through a specific meridian system [5].
Ancient acupuncture theory explains that the human body circulates vital element of life, namely Hawa (ci) and blood (sie), which flows in a network called meridians. When homeostasis is disrupted, the corresponding acupuncture points begin to be active, and there is a decrease in the pressure threshold. This causes pain to appear when pressed on certain parts of the body and if more active it will feel painful even without being pushed. This occurs at regular acupuncture points (common nodes) and Ase points, and at the Ase point changes in mechanical pressure thresholds change according to disease occurrence, and the location is also in accordance with the area of disturbance occurring and often has nothing to do with nerve reflexes (local reaction). A decrease in electrical resistance and a change in temperature around the active area (becomes warmer). If a disturbance occurs, a series of physiological changes will occur, from inflammation, swelling, abscesses, pain in certain parts and other changes as a result of proinflammatory reactions that can be explained through the Inflammatory Reflex Theory, active acupuncture points are the results of active sensory nerves in question, the mechanism of acupuncture is only stimulating and the healing system is the body itself [3].

\section{Acupuncture Technique}

There are 4 stabbing techniques, namely: perpendicular puncture, oblique puncture, almost horizontal puncture, and horizontal puncture.

1. Upright puncture, which is to insert a needle perpendicular to 90 degrees above the skin. This method is most often practiced.

2. Angled puncture, which is to insert a needle about 45 degrees above the skin. This method is often used in the head, chest and wrist.

3. Nearly horizontal puncture, which is thrusting a needle about 30 degrees, 
Review: Study the Role of China Acupuncture and "GI" Acupuncture as an Alternative and Complementary Therapy in the Treatment

also known as "Subcutaneous Puncture". This method is used in thin places, for example on the head.

4. Horizontal punctures, also known as "Modern Punctures", insert needles smaller than 30 degrees almost 12-15 degrees. This method uses longer or even long needles so that several points can be reached at once. This method is obtained from the Science of Analgesia-Acupuncture and is performed on the skin of the abdomen and extremities [6].

\section{Acupuncture Safety}

Acupuncture/needling

is

stimulation or stimulant in the body's regulatory system to work better if there is a disruption or imbalance. Acupuncture works to stimulate the nervous system based on the principle of self healing power so that the body will repair itself and the interference that is happening. Therefore, acupuncture is not compelling [7].

The World Health Organization, WHO, as well as Western health agencies such as the NIH or the National Center for Complementary and Alternative Medicine (NCCAM) and the American Medical Association (AMA), stipulates that the point of needling treatment is safe to use while using sterile needles and is carried out by trained, competent, and in accordance with procedures. In addition, in its 2002 publication entitled Guidelines on Basic Training and Safety in Acupuncture, WHO states that acupuncture is non-toxic and has low side effects and is accompanied by an explanation of the training grounds and what conditions are needed to be able to practice safe and quality acupuncture. Therefore, until now this technique still survives throughout the world, although the development of the method is far behind that of Western medicine [8].

\begin{abstract}
Akupunktur "GI"
GI acupuncture is a breakthrough needle that was developed by Gunawan Ismail for more than 40 years and has been practiced directly, analyzed, as well as supported by traditional needling literature and Western method medical books to produce new needling methods on the basis of Western anatomy and physiology. Examination and diagnosis also use medical theory, so the basics of old theories such as Yin Yang that are used for basic acupuncture are not used anymore. In this GI needle puncture the needling point is much simpler and there are not as many as the ancient needling points based on 14 meridians with 361 needling points. This GI needle stitch is being developed also through scientific research at the Bandung Institute of Technology (ITB) [3].
\end{abstract}

\section{Characteristics of "GI" Acupuncture}

The "GI" acupuncture method offers a method of acupuncture therapy that comes from Eastern Medicine, but with an anatomical and physiological foundation of Western Medicine. With the use of more simple and measurable acupuncture points. This acupuncture method is an Indonesianstyle acupuncture method developed by Gunawan Ismail and published in a book entitled Healthy without Drugs with Needle-style Indonesian Style. The characteristics of the "GI" acupuncture method are as follows:

1. Te Chi, is a term used for the characteristics of universal acupuncture or needling therapy. Needle puncture must provide a certain sensation felt by the patient.

2. In determining the diagnosis of a patient's disease, acupuncture "GI" uses a diagnostic method of Western medicine, namely anamnesis, physical examination, and if necessary a supportive investigation (laboratory, radiology). Whereas Classical Acupuncture determines the selection of 
points based on the diagnosis of the way of Eastern Medicine (yin and yang examination).

3. "GI" acupuncturists prioritize 2-3-2 acupuncture points for the majority of systemic metabolic and degenerative disorders. Acupuncture works through access to the nervous system. It is known that the point in the stomach is very effective for stimulating the autonomic nerve, which is one of the main components of the regulator of nerve fast track homeostasis that works when stress occurs along with other hormonal components and is a slow pathway.

4. The 2-3-2 acupuncture point means taking 2 points in the neck located behind the right and left ears, 3 points in the abdomen ( 1 point in the pit of the stomach, 2 points on the right and left edges of the umbilicus), 2 points in the right and left lower limbs under the knee. The classical acupuncture method determines the point based on axis and ordinate mapping at a certain distance automatically in the human body (cun or even distribution). The "GI" acupuncture method determines acupuncture points based on palpation based on the ability of massage, so that the determination of points 2-32 in each patient is not always uniform, because the most hardened / spasm of the muscle is sought.

5. GI" acupuncture also takes symptomatic points (Ase Points) as done in the classic acupuncture method. The addition of several points on the "GI" acupuncture adopted the points used in classical acupuncture, with stabbing adjusted to palpation / massage before at that point [3].

\section{Advantages of "GI" Acupuncture} include:

The benefits of GI needling

1. Shows excellent results for stressful cases

2. The basis of Western medical theory facilitates its development so that new methods can be sought that are more effective in treating diseases.

3. Based on 12 years of experience in the care of athletes in the Badminton National Park, this needling can overcome muscle and joint injuries, overcome tension before competing, and fatigue after a match.

4. The analytical theoretical basis used can make this new model needles as a tiered non-academic field, from the beginner to the end.

5. The side effects caused are almost nonexistent because the implementation does not use chemical drugs.

6. Needling is only stimulation or stimulant that stimulates the body's regulatory system to work better if there is interference. Actually what works is the body's own system, not the needling [3].

\section{Some Research Related to Acupuncture "GI"}

Several studies conducted on stroke patients, fibromyalgia and hypertension regarding the benefits of acupuncture therapy "GI" showed "GI" acupuncture to provide meaningful results.

\section{The Role of "GI" Acupuncture Therapy in Stroke Patients \\ WHO (World Health Organization) states that acupuncture is an effective treatment for stroke cases. This study aims to examine the role of clinical "GI" acupuncture therapy in stroke patients. The observational study was carried out for \pm 3 months for stroke patients treated with "GI" Acupuncture at Sukamenak Acupuncture Clinic and UPT Bumi}


Medika Ganesha ITB. The parameters studied were the Barthel Index, the Motivation Index, and the patient's handgrip strength. The test results are determined statistically by paired t-test method. After 2 months (16 times of therapy) there is an increase in mean Barthel Index score was significantly $(\mathrm{p}<0.05)$ of $68.70 \quad( \pm 33.56)$ to 81.00 $( \pm 24.51)$, the mean total score Motrisitas Index $(\mathrm{p}<0.05)$ from $212.59( \pm 74.70)$ to $253.27( \pm 40.72)$, and mean handgrip strength $(\mathrm{p}<0.05)$ from $5.74( \pm 6.66) \mathrm{kg}$ to $9.72( \pm 8.42) \mathrm{kg}$. From these data, it can be seen that "GI" Acupuncture plays an effective role in increasing the motor activity of stroke patients which is shown through increased independence in carrying out daily activities,increased ability to control the body and perform various movements, and increase physical strength [4].

\section{The Role of "GI" Acupuncture in Fibromyalgia therapy}

In this study concurrent and qualitative observational studies were carried out for \pm 4 months through interviews with the main parameters FIQ (Fibromyalgia Impact Questionnaire) and muscle strength measurements with a hand dynamometer especially in fibromyalgia patients with major complaints in the arm area and its surroundings. The results showed that there was a significant difference $(p<0.05)$ between a decrease in FIQ scores and the number of "GI" acupuncture therapies. In the correlation test also found a positive value that indicates a relationship where the more the number of "GI" acupuncture therapy, the lower the FIQ score also increases [7].

\section{The Role of "GI" Acupuncture in Hypertension Therapy}

In this study an assessment of the role of "GI" acupuncture in the treatment of hypertension was carried out, which was associated with a decrease in blood pressure and the appearance of symptoms of hypertension. Qualitative observational studies were carried out qualitatively, namely directional interviews for filling out questionnaires and quantitatively by measuring respondents' blood pressure, The study was conducted over a period of four months, the results obtained during the investigation were that overall hypertensive respondents in all groups (sex and other illnesses suffered) had decreased systolic and diastolic blood pressure as the number of "GI" acupuncture therapies increased, Hypertensive respondents experienced symptom improvement during their "GI" acupuncture therapy. The role of "GI" acupuncture therapy as a complementary therapy is effective in reducing the appearance of hypertensive symptoms but cannot reduce blood pressure directly [15].

\section{Stress and Management}

According to Selye [9], stress is a general response to demands on the body. These demands are a necessity to adjust, and therefore the body's balance is disturbed. Stress begins with an alert reaction (alarm reaction) to the presence of threats that are characterized by bodily processes automatically, such as increased heart rate which is then followed by a reaction to resistance to stressors and will reach exhaustion if the individual is unable to continue to survive. Every individual in his life always faces various unpleasant problems. In fact stress is an individual reaction in dealing with every event that happens around it. The presence of stress can affect an individual's ability to deal with the environment. Atkinson, said stress arises due to excessive demand that cannot be met so that it can threaten a person's physical and psychological well-being [10].

According to Hager, stress is very individual and basically destructive if there 
Review: Study the Role of China Acupuncture and "GI" Acupuncture as an Alternative and Complementary Therapy in the Treatment

is no balance between the individual's mental endurance and the burden he feels [11]. However, dealing with a stressor (source of stress) does not always result in psychological or physiological disorders. Whether or not a person is disturbed, depends on his perception of the events he experiences. The key factor of stress is one's perception and assessment of the situation and its ability to deal with or take advantage of the situation at hand. In other words, that reaction to stress is influenced by how the individual's mind and body perceive an event. Sarafino, mentions stress arises as a result of the gap between the demands generated by transactions between individuals and the environment with biological, psychological or social systems owned by these individuals that will influence their cognition, emotions and social behavior [12].

The same stressors can be perceived differently, which can be a positive and harmless event, or a dangerous and threatening event. individual cognitive assessment in this case seems to be very decisive whether the stressor can have a positive or negative effect. Cognitive assessment is very influential on the response that will appear [11].

Based on the description above, it can be concluded that stress is an internal condition that can damage and physical and psychological harm individuals as a result of a mismatch between the demands of the environment with individual ability to respond. Stress management is a very individual thing and there is no stress management technique with the best techniques. Effective management programs must be practiced consistently and choose the techniques that are most suitable for the individual concerned.

One of the best in stress management is to prevent it, by managing stress from now on, to prevent future illnesses. If it happens what can be done is to minimize the amount of damage.
Primary, secondary and tertiary prevention of stress:

1. Techniques to avoid exposure to stressors (i.e., primary prevention) :

a. Avoiding stress is known,

b. Get used to having a healthy personality and polite behavior,

c. Identification, and restructuring of cognitive distortions associated with stressful events,

d. Planning and priority,

e. Maintenance of physical health and mental well.

2. Techniques to minimize the level of stimulation of someone affected by stressors (ie, secondary prevention):

a. Minimization of physiological stimuli using relaxation and exercise techniques.

b. Verbalization.

c. Support from others.

d. Use of anxiolytics.

e. Use of techniques to avoid exposure to stress.

3. Techniques to reduce levels of stress stimulation (tertiary prevention) :

a. Catharsis: an therapeutic technique in which ideas, thoughts, fears, disappointments and material emphasis are expressed to produce a free state for individuals,

b. Inspiration: the process of experiencing a sense of optimism where one recognizes the ability to overcome challenges.

c. Acceptance by others: individuals come to the realization that other people understand, help to correct guilt,

d. Universalization: people come to the realization that their experiences are not unique.

e. Use of techniques to avoid stress exposure and to minimize the level of stress stimulation that is once exposed to stressors [13]. 
Handling stress from an early age can prevent the increasing severity of stress levels that can lead to a level of depression so that it can cause psychiatric illnesses that are crazy.

\section{Impact of Acupuncture Therapy on Stress}

Many rely on acupuncture for slimming, healing heart disease, and overcoming blood sugar levels. But, it is known that the art of needle piercing from China apparently also can reduce stress levels.

Judging from the Daily Mail, a team of US researchers has proved useful to stress after conducting a series of studies on the therapeutic benefit of the Chinese ancient. In his study, the research team found that acupuncture can reduce the level of chronic stress-related proteins, namely neuropeptides. using experimental mice, the researchers believe the findings could be an alternative therapy to deal with stress.

They tested the effect of acupuncture on the levels of neuropeptide proteins in the blood, which are secreted by the sympathetic nervous system in humans. This study used four groups of mice during the 14-day trial period. The first group was the control group that was not stressed and did not receive acupuncture. The second group was a group who was stressed for one hour a day and did not receive acupuncture. The third group was the group that was stressed and received acupuncture near the tail. Meanwhile, the fourth group was a stressful experimental group and received acupuncture.

Lead author Dr. Ladan Eshkevari from Georgetown University, conditioned the rat to rest by crawling into small socks, and gently make mice comfortable with electroacupuncture stimuli. This form of therapy provides more intensive results than ordinary acupuncture. Then, he chose an acupuncture point that was known to help alleviate various conditions including stress. In mice, the point is located below the knee. Dr. Eshkevari found that the levels of neuropeptide proteins in the experimental group fell almost equivalent to the levels of neuropeptide proteins in the control group. Meanwhile, the group of stressed mice not treated with acupuncture had high levels of neuropeptide proteins. In the second trial, he stopped acupuncture therapy in the experimental group, but continued to make stressed mice for four days. As a result, the neuropeptide protein remains low. Although it's known that acupuncture can reduce stress, this research is the first study to prove this. And from the results of this study showed a satisfying effect, namely protection against stress received after therapy [14].

The results of research conducted by Risna et al., In their study found that a person diagnosed by a doctor was experiencing stress and then performed acupuncture therapy regularly, twice a week with a span of 2 days after taking acupuncture therapy, showed significant results in decreasing stress scores compared with patients who did not undergo the therapy [16].

\section{CONCLUSION}

Based on the literature review it is known that acupuncture can provide excellent results in handling stress through decreasing levels of neuropeptide proteins in the experimental mouse group and stress patients at the Ganesha Medica Clinic. See related literature acupuncture "GI" that provides meaningful activity in improving the quality of life of patients with stroke, fibromyalgia, and stress, this is the main attraction for unknown whether acupuncture "GI" can provide meaningful activities also in the treatment of patients with depression. Depression is a matter for each individual, and if not appropriately handled then the level of depression may increase and will impact on health. In this case acupuncture offers a safer offer in 
handling depression than if an individual suffering from depression must take drugs, it is known that each drug must have side effects. This is what attracts attention to do research on the extent to which the benefits of GI acupuncture therapy, namely acupuncture developed in Indonesia based on Javanese massage points, to decrease the level of depression in individuals suffering from depression.

\section{REFERENCES}

[1] Guan YJ. Xiang J.J. and Jin L. Contemporary Medical Acupuncture - A System Approach. Beijing : Higher Education Press 277-278 ; 2006

[2] Zhang XR. Acupuncture: Kajian and Analysis of Reports on Controlled Clinical Trials. Geneva : World Health Organisation $5 ; 2002$

[3] Ismail G. Sehat Tanpa Obat dengan Tusuk Jarum Ala Indonesia. Jakarta : Grasindo 40-82 ; 2009

[4] Haryono DC. Soemardji AA. Dan Fanty F. Peranan Terapi Akupunktur "GI" Pada Penderita Stroke. JKM: ISSN -1411-9641, 142, Vol.10. 2011

[5] Saputra K. Akupunktur Dalam Pendekatan Ilmu Kedokteran. Surabaya : Airlangga University Press ; 2000

[6] Calehr H. Pedoman Akupunktur Medis Jilid 1 Pengetahuan Dasar. Jakarta: Gramedia Pustaka Utama $140 ; 1986$

[7] Erlinda O. Peran Akupunktur "GI" Dalam Penekanan Gejala
Fibromyalgia, (skripsi). Bandung: Sekolah Farmasi-ITB 8-9 ; 2011

[8] Zhang XR. Guidelines On Basic Training And Safety In Acupuncture. Geneva : World Health Organisation $19-20 ; 2002$

[9] Santrock JW. Aldocense (perkembangan remaja). Translation by Soejarwo. Jakarta : Erlangga ; 2003

[10] Atkinson R.L dkk. Hilgrands Introduction to Psychology. Ed 13th. Ney York : Harcourt College Publisher ; 2003

[11] Sarafino E. Health psychology Biopsychosocial interaction. Ed 5th. USA : John Wiley \& Sons.Inc ; 2006

[12] Bryce CP. Insights into the Concept of Stres. Washington D.C : WHO ; 2001

[13] Eshkevari., L. (2011): Acupunkture Prevents ChronicStres Induced Increasesin Neuropeptide $Y$ in Rat. Washington. Georgetown University Medical Centre. Diakses melalui. http://ebm.rsmjournals.com

[14] Mutiara APA. Peran Akupunktur "GI" Dalam Terapi Hipertensi, (skripsi).Bandung: Sekolah FarmasiITB ; 2011

[15] Agustina R, Soemardji A (2016). The Effectiveness of " GI Acupuncture" to The Stress Treatment In Patients at Sukamenak Acupunture Clinical and UPT Health Services Bumi Medika Ganesa ITB. Jurnal Sains dan Kesehatan, Vol 1. Issue. 5 